\section{CORRUPÇÃO E PADRÕES DE INEFICIÊNCIA NAS GESTÕES MUNICIPAIS DETECTADOS POR CORTE DE CONTA ESTADUAL}

\author{
Clóvis Alberto Vieira de Melo \\ José Wilas Pereira
}

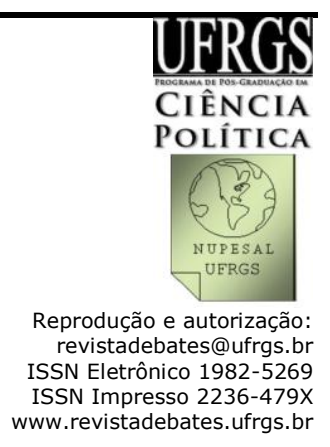

Resumo

Identificar o que motiva reprovações de prestações de contas de municípios por parte de Tribunal de Conta Estadual é o principal objetivo deste trabalho. Para tanto se testou duas hipóteses principais, quais sejam a existência de casos de corrupção e impropriedade administrativa, esta última envolvendo casos de negligência, imprudência e ou imperícia. O levantamento de dados abrangeu quase a totalidade dos municípios do estado da Paraíba em anos da gestão 2005-2008. Nos testes empíricos, em que foi utilizada regressão logística binária, as hipóteses sugeridas foram corroboradas, pois apresentaram significância estatística. As chances de um gestor municipal ter suas contas rejeitadas aumentam em torno de 35 vezes quando da presença de casos de corrupção. Já quando há impropriedades administrativas as chances se ampliam em aproximadamente 13 vezes. A pesquisa constatou também que há discrepâncias importantes no julgamento por parte do Tribunal de Contas do Estado da Paraíba e do Ministério Público daquele estado, este último se apresentando mais rigoroso. Descobriu-se também que prefeitos correligionários do governador do Estado não tiveram suas contas julgadas diferentes de prefeitos de outros partidos.

Palavras-chave: Corrupção; Impropriedade Administrativa; Tribunal de Contas Estadual.

\begin{abstract}
Identify what motivates disapprovals rendering of accounts of municipalities by the State Court of Account is the main objective of this work. For that we tested two main hypotheses, namely the existence of corruption and administrative impropriety, the last one involving cases of negligence and imprudence or malpractice. The survey covered almost all the municipalities of Paraíba state management in years 2005-2008. In empirical tests, in which we used binary logistic regression, the hypotheses suggested were corroborated as statistically significant. The chances of a city manager have their accounts rejected increase around 35 times when the presence of corruption. Have administrative improprieties the chances are enhanced by approximately 13 times. The survey also found that there were important discrepancies in judgment by the Court of Auditors and Public Prosecutors of Paraíba, the last one being more stringent. It was also discovered that fellow mayors of the State Governor had not their accounts judged different of mayors from other parties.
\end{abstract}

Keywords: Corruption; Administrative Impropriety; State Court of Auditors. 


\section{Introdução}

Bons governos, que sejam responsáveis, responsivos e eficientes na alocação de recursos públicos é o que espera a maior parte dos eleitores ao fazer suas escolhas nos pleitos eleitorais. Mas, para tanto, governantes necessitam de expertise burocrática e probidade na administração pública. A primeira estando diretamente relacionada aos níveis de acertos e erros na execução de políticas, ou seja, ao nível de ocorrência de impropriedades, que são caracterizadas por casos que envolvam negligência, imperícia e imprudência por parte do gestor público, e a segunda relacionada com gestores probos, que perseguem a integridade do erário, e que coíbam desvios de recursos ou corrupção.

No sistema político brasileiro cabe ao Poder Executivo, nas suas diferentes esferas, a execução da maior parte das políticas públicas. Em nível municipal o prefeito detém grande parte dessa responsabilidade, em especial as relacionadas com a área social, o que Ihes é conferida pelos eleitores, que por sua vez esperam que suas demandas sejam atendidas a contento.

É possível constatar na literatura que toma como objeto de análise as gestões municipais um cenário em que impropriedade e corrupção, diferente do que se espera, são regra e não a exceção (MENDES, 2004; FERRAZ e FINAN, 2006 e 2007; BROLLO, 2008; LEITE, 2009; MELO, 2010). Isso fica evidente a partir de detecção dessas irregularidades por parte de sistemas de controle, em especial as cortes de contas, as quais terminam por recomendar reprovações das ações de gestores municipais. Estas reprovações constituem um fenômeno recorrente nessas gestões (PEREIRA e CORDEIRO FILHO, 2012) e crescente segundo Rezende (2009). Explicar as causas dessas reprovações é a questão central a ser respondida nesse trabalho.

Trata-se de uma pesquisa descritivo-explicativa, que tem como objeto as gestões municipais do estado da Paraíba, em anos situados entre 2005 e 2008. Os dados foram coletados por meio de análise de documento, particularmente, os acórdãos do Tribunal de Contas do Estado da Paraíba (TCE), e em seguida tratados quantitativamente, o que possibilitou a elaboração de um banco de dados e um posterior diagnóstico dos principais problemas envolvendo as gestões públicas municipais da Paraíba. Dentre as variáveis pesquisadas, destacam-se os casos de corrupção, bem como impropriedades administrativas, que constitui as duas principais hipóteses testadas para explicar reprovações de contas por parte do TCE.

Descritivamente, os resultados mostraram que foram encontrados casos de corrupção em $27 \%$ dos municípios analisados, e em $86 \%$ destes, casos de impropriedade administrativa. Isto sugere que as variáveis explicativas para reprovações de contas são presentes e intensas nos municípios estudados, o que foi corroborado pelos testes inferenciais, os quais apresentaram significância estatística e forte poder explicativo. Além disso, a pesquisa mostrou que há discrepância entre o julgamento da Corte 
de Conta estadual e do Ministério Público da Paraíba (MP) junto ao TCE, sobretudo, no rigor das recomendações.

O texto está divido em quatro partes principais. Num primeiro momento é feita uma reflexão sobre corrupção e impropriedade administrativa presentes nas gestões públicas, que são compreendidas como um problema de agência, que é inerente do processo de delegação presente na relação principal-agente. Posteriormente se procede a uma discussão sobre os mecanismos restritivos e de combate aos problemas de agência, tendo centralidade nesse debate os sistemas de accountability, em especial o papel das cortes de contas. Em seguida são apresentados os caminhos metodológicos percorridos na pesquisa e os principais resultados. E por último as principais conclusões.

\section{Corrupção, impropriedades adminstrativas e problemas de agência}

A partir da constituição de 1988 os entes subnacionais no Brasil ganharam destaque na execução das políticas públicas, visto que passaram a ter um maior número de prerrogativas. Segundo Arretche (1999) até o início da década de 1980 no Brasil as relações entre os diferentes entes federativos se aproximavam muito mais de um modelo de estado unitário do que federativo. Durante o regime militar governos estaduais e municipais tiveram fortes diminuições de sua autonomia política e fiscal. Os principais tributos eram concentrados no governo federal, e cabia a estes transferir recursos para os entes subnacionais, os quais eram rigorosamente controlados em suas ações.

Ao longo da década de 1980 a estrutura do estado brasileiro passou por um conjunto de reformas que terminaram por iniciar uma redefinição dos papeis dos entes federados. Os governos subnacionais, sobretudo, a partir de um novo design advindo da constituição de 1988, passaram a ser dotados de soberania e autonomia política e fiscal. Estados e municípios não mais dependiam do aval do governo central para tomada de decisões, consolidando-se assim um modelo federativo em que cada ente possuía suas competências e atribuições.

O poder dos estados e municípios se ampliou consideravelmente, já que passaram a tributar nas áreas de suas competências, houve um aumento das transferências intergovernamentais, bem como ocorreu um processo de descentralização das políticas administradas pelo governo federal, sobretudo, as relacionadas com proteção social. Estados e municípios, portanto passam a gerenciar políticas públicas, que se dão "[...] por própria iniciativa, ou por adesão a algum programa proposto por outro nível mais abrangente de governo, ou ainda por expressa imposição constitucional" (ARRETCHE, 1999, p. 4).

Se antes o governo federal centralizava as decisões políticas e administrativas, em fins dos anos 1980 e, sobretudo, nos anos 90 passou a 
delegar aos outros entes federados função de gestão de políticas públicas em diversas áreas, tais como:

[...] saúde, habitação, saneamento básico e assistência social. Em 1997 [...] a oferta de merenda escolar era inteiramente gerida por estados e municípios; $58 \%$ dos municípios brasileiros estavam enquadrados em alguma das condições de gestão previstas pelo SUS, o que significa que estes assumiram funções de gestão da oferta local de serviços de saúde até então desempenhadas pela União; $69 \%$ das consultas médicas eram realizadas através de prestadores estaduais ou municipais, sendo que, destas, $54 \%$ eram prestadas pelos municípios, o que significa que mais da metade das consultas médicas passaram a ser oferecidas por prestadores municipais, os quais eram, até o final dos anos 80 - respeitadas às exceções -, o nível de governo menos envolvido na oferta de serviços de saúde [...] (ARRETCHE, 1999, p. 115).

Diante desse quadro se questiona: até que ponto os entes subnacionais, em especial os municípios, têm desempenhado adequadamente as funções que Ihes foram atribuídas, conseguido dessa forma gerar bons governos? Os achados da literatura sugerem que a qualidade da gestão está distante do ideal, bem como os casos de corrupção são fortemente presentes.

A grande maioria das irregularidades encontradas nas gestões públicas municipais está relacionada com a incapacidade administrativa em executar ações governamentais de maneira eficiente. Sabe-se que a qualidade da burocracia é fator fundamental para que estas ações ocorram a contento, no entanto, os dados empíricos mostram que imperícia, negligência, imprudência, entendidas aqui como impropriedades, ocorrem na grande maioria dos municípios brasileiros e com muita intensidade (MELO, 2010). Isso em grande medida está relacionado à qualidade da burocracia, que pode ser medida, dentre outros indicadores, pelos níveis de formações dos funcionários das prefeituras municipais no Brasil. Verifica-se que aproximadamente $20 \%$ destes possuem nível superior e um terço de todos os funcionários possui apenas o ensino fundamental (Tabela 1). Isto indicado que os gestores públicos municipais possuem uma burocracia dotada de baixo know-how, o que pode influenciar diretamente na qualidade dos serviços prestados. Funcionários com baixa qualificação são mais propícios a cometer impropriedade, ou seja, erros ao executarem suas funções, o que é agravado pela presença de corrupção, fenômeno que explica para maus governos (CAIDEN, 1981). 
Tabela 1 - Escolaridade dos Funcionários da Administração Municipal Direta por Regiões do Brasil e Paraíba - 2008

\begin{tabular}{l|c|c|c|c|c|c}
\hline Região & \multicolumn{5}{|c}{ Escolaridade (\%) } \\
\hline & $\begin{array}{c}\text { Sem } \\
\text { Instrução }\end{array}$ & $\begin{array}{c}\text { Ensino } \\
\text { fundamental }\end{array}$ & $\begin{array}{c}\text { Ensino } \\
\text { Médio }\end{array}$ & $\begin{array}{c}\text { Ensino } \\
\text { superior }\end{array}$ & $\begin{array}{c}\text { Pós- } \\
\text { graduação }\end{array}$ & Total \\
\hline Brasil & 3,0 & 30,2 & 41,4 & 21,0 & 4,4 & 100 \\
\hline Norte & 3,4 & 29,8 & 47,7 & 17,1 & 2,0 & 100 \\
\hline Nordeste & 4,2 & 28,1 & 46,3 & 18,6 & 2,8 & 100 \\
\hline Sudeste & 2,9 & 33,4 & 37,6 & 23,4 & 2,7 & 100 \\
\hline Sul & 1,7 & 28,8 & 37,8 & 22,6 & 9,1 & 100 \\
\hline $\begin{array}{l}\text { Centro- } \\
\text { Oeste }\end{array}$ & 2,6 & 30,3 & 40,9 & 20,6 & 5,6 & 100 \\
\hline Paraíba & 5,5 & 31,7 & 38,5 & 21,0 & 3,4 & 100 \\
\hline
\end{tabular}

Fonte: IBGE.

De fato, os erros são a regra e não a exceção nas ações em gestões municipais. Em pesquisa que tinha como objeto de análise os relatórios da Controladoria Geral da União (CGU) acerca das execuções municipais envolvendo verbas do governo federal, Melo (2010) constatou que em $91,5 \%$ deles existiam casos de impropriedades. Na mesma pesquisa, verificou-se que em $63,5 \%$ dos municípios analisados havia casos de corrupção. Esse quadro corrobora números levantados por Mendes (2004) em verbas relacionados com o Fundo de Manutenção e Desenvolvimento do Ensino Fundamental (FUNDEF). Irregularidades envolvendo gestões municipais também foram pesquisadas por Ferraz e Finan (2006 e 2007), Brollo (2008) e Leite (2009).

Corrupção e impropriedade na administração pública configuram-se como um problema principal-agente, que no limite significa perda de agência (agencyloss), esta entendia nos moldes de Pratt e Zeckhauser (1985), para os quais é o resultado da diferença entre o que é delegado pelo principal e o que de fato é executado pelo agente. ${ }^{1} \mathrm{Na}$ gestão pública

\footnotetext{
${ }^{1}$ Desenvolvendo-se dentro da relação principal $x$ agente e nos limites da delegação, o termo perda de agência (agencyloss) é amplamente usado pela literatura para identificar casos onde ocorra algum descumprimento, ou mesmo negligência, no acordo firmado entre as partes. Pratt e Zeckhauser (1985) argumentam que isso ocorre quando o agente além de não cumprir adequadamente com suas atribuições faz prevalecer seus interesses, desconsiderando os do principal. Nos moldes da teoria principal-agente agencyloss acontece, por exemplo, quando o governo (agente) não cumpre adequadamente com os compromissos firmados com os cidadãos (principal), ou quando os políticos, na condição de principal, delegam a burocratas (agentes) determinadas tarefas, e estes dispondo de informações privilegiadas não cumprem de maneira satisfatória suas atribuições. Sobre este aspecto, há para o principal um risco moral (moral hazard), o que pressupõem uma substantiva dose de confiança nesta relação, ou seja, o delegante terá de confiar no agente e torcer para que ele cumpra com o seu compromisso adequadamente. Delegar significa, inevitavelmente, um ganho de autoridade, por parte do agente, se ambas as partes (principal e agente) decidirem maximizar suas utilidades, o agente dificilmente agirá no melhor interesse do principal. Por isso, a delegação implica sempre num custo de agência (Jensen e Meckling, 1976). Pois, o principal jamais conseguirá, a um custo zero, alinhar o interesse do agente ao seu. Neste sentido, a literatura sugere que os problemas de agência estão diretamente relacionados a assimetrias informacionais, conflitos de interesse e custos de monitoramento dos agentes.
} 
o agente pode cumprir adequadamente sua função ou não. Pode optar por ser eficiente, buscando para tal reduzir custo e atingir maior e melhor resultado, ou o inverso, tornado mais custoso o investimento, quer seja capturando recurso através de ações corruptas, ou simplesmente negligenciando suas funções.

Na Carta Magna de 1988, ao lado de outros princípios, eficiência ganhou status de princípio constitucional na administração pública, conduzindo os gestores a observarem a relação custo/benefício de suas ações, para isso fazendo um "[...] balanço entre os objetivos atingidos e os recursos utilizados para tal [...]" (GOMES, 2009, p. 20).

Sendo assim, governos que desperdiçam recursos e não conseguem, consequentemente, dar vazão às demandas sociais ou atendendo-as de maneira inadequada caracterizam-se como ineficientes. Este problema reside na incapacidade dos agentes públicos em prestar serviços compatíveis com as necessidades da população e seu resultado constitui agencyloss.

Corrupção, no setor público, aqui entendido como a ação de agente público em parceria com outro externo, de forma voluntária, captura recursos públicos para benefícios pessoais em detrimento do interesse público, resulta igualmente em agencyloss, já que ao capturar recursos o agente deixará de executar a política pública tal qual foi concebida, ficando dessa forma distante de atingir seu ponto ótimo, já que no limite não cumpre adequadamente a função que lhe foi delegada.

Como então diminuir os níveis de agencyloss provocados por corrupção e impropriedades administrativas? Becker (1968) sustenta que sistemas de controle e punição operam como instrumentos restritivos a comportamentos desviantes na administração pública, em especial corrupção. Na perspectiva do controle dos agentes públicos, o papel dos mecanismos de accountability ganha centralidade. Sugere-se que menores serão os episódios de captura de recursos públicos, por exemplo, se os instrumentos de accountability forem fortes e eficazes. Em outras palavras, o incremento pelo Estado de instrumentos de responsabilização com atuação incisiva nas diferentes esferas de governo, traduz-se numa redução dos incentivos a ações lesivas aos cofres públicos.

Para Lindberg (2009) a ideia central que norteia a responsabilidade governamental é o princípio da delegação o qual deve estar sempre atrelado à avaliação das realizações e a imposição de sanções. Segundo ele, sempre que a tomada de decisão for transferida para um agente, o principal deve dispor de mecanismos para mantê-lo prestando contas de suas decisões e sendo passível de punição, quando necessário for.

Accountability, por este prisma, está relacionada à efetivação de mecanismos que possibilitem a prestação de contas dos governos para com a sociedade e a avaliação que esta, e os demais órgãos de controle pretendam realizar sobre aqueles. Classicamente, ela se manifesta de três formas: horizontal, vertical e societal. Esta última sendo uma forma de controle exercida pela sociedade civil, com o apoio, sobretudo da mídia e 
dos movimentos sociais sobre os governantes. Accountability vertical, na relação principal-agente, ocorre de maneira direta, através do voto do eleitor (principal) para com os governantes eleitos (agentes), onde estes podem ser punidos ou premiados a depender da performance do seu governo.

Accountability horizontal, por outro lado, ocorre mediante trabalho integrado de instituições componentes do aparato de Estado criados com a finalidade de desenvolver atividades de controle. $O$ conceito de accountability horizontal utilizado nesse trabalho segue os termos de O'Donnell (1998).

No caso brasileiro, esse tipo de controle ocorre em todos os níveis de governo, e para tanto se lança mão de instituições técnicas de controle, a exemplo de controladorias e cortes de contas existentes em nível federal, nos estados e, em alguns casos, nos municípios.

Em âmbito municipal accountability horizontal, é exercida pelas câmaras municipais, auxiliados por tribunais de contas estaduais, e em um número reduzidos de casos por cortes de contas municipais, os quais têm como objetivo avaliar as contas municipais em relação ao cumprimento das diretrizes orçamentárias determinadas em lei.

\section{Instrumentos de Accountability e cortes de contas no Brasil}

Não são recentes as discussões, que envolvem mecanismos de controle de recursos públicos. ${ }^{2} \mathrm{Em}$ menor ou maior escala, esse debate acompanha as diferentes evoluções sociais e a engenharia institucional que desenha a própria estrutura de Estado. Este sendo utilizado, nesse trabalho, nos termos de Giddens (2001, p. 42), para o qual os órgãos administrativos de governo, por características que Ihes são intrínsecas, constituem o espaço central para o debate sobre controles institucionais, dado que, na prática, é quem gerencia interesses e recursos da sociedade.

A centralidade do aparato de Estado, nesse debate, não exclui ou, pelo menos, não deveria excluir - a sociedade, porquanto, em última instância, é a ela que os agentes estatais devem prestar contas. Essa prestação de contas pode ocorrer em duplo sentido: num primeiro cenário, o agente pode informar à sociedade acerca de suas ações na administração pública e, no sentido inverso, a sociedade pode buscar essas informações, independentemente da iniciativa do agente estatal, quer de forma direta (através de mecanismos como, por exemplo, Comissão Especial de Inquérito - $\mathrm{CEI}$ ), quer de forma indireta (por meio de órgãos possuidores de delegação para esse fim, a exemplo dos parlamentos, nos seus diferentes níveis) ${ }^{3}$.

\footnotetext{
${ }^{2} \mathrm{O}$ conceito de controle é entendido nesse trabalho como a faculdade de vigilância, orientação e correção que um Poder, órgão ou autoridade exerce sobre a conduta funcional de outro (SOUTO, 1999, p. 32).

3 Comissão criada pelo Decreto n. 1.001, de 6 de dezembro de 1993, editado pelo então Presidente da República, Itamar Franco, à conta das crises políticas e institucionais ocorrida
} 
Dentre os elementos componentes do aparato de Estado, as estruturas que objetivam fiscalizar e controlar a aplicação dos recursos públicos vem ganhando atenção por parte da sociedade. Elas se subdividem em dois tipos clássicos: o daquelas que exercem o controle interno e o das que exercem o controle externo. Essa divisão têm origem em preocupações distintas, como demonstra Speck no trecho a seguir:

[...] primeiro na preocupação gerencial de administrar bem os recursos públicos. Essa preocupação nasce no âmbito da própria administração, e dá origem a instituições de controle financeiro, inicialmente alocadas no âmbito do próprio poder executivo. A segunda fontedas instituições de controle financeiro é a apreensão liberal com limitação do poder executivo[...] (SPECK, 2000, p. 31).

\subsection{Controle interno}

O sistema de controle interno tem por finalidade produzir informações acerca de como está sendo desempenhado o trabalho dos mais diferentes órgãos administrativos, verificando, para isso, dentre outros, o cumprimento de metas, a legalidade dos atos e os resultados, quanto à eficácia e eficiência das ações implementadas. O controle interno visa, assim, dar ao administrador melhor condição de decisão, no que se refere a sua administração, fazendo com que ele identifique problemas, tais como impropriedades ou corrupção, e proceda com as medidas corretivas e punitivas necessárias. Meirelles define controle interno como sendo:

[...] todo aquele que o Executivo e os órgãos de administração dos demais Poderes exercem sobre suas próprias atividades, visando mantê-las dentro da lei, segundo as necessidades do serviço e as exigências técnicas e econômicas de sua realização, pelo que é um controle da legalidade e de mérito. Sob ambos esses aspectos podem e devem operar-se com legitimidade e eficiência, atingindo a sua finalidade plena, que é a satisfação das necessidades coletivas e o atendimento dos direitos individuais dos administrados [...] (MEIRELLES apud SANTOS, 1997, p. 18).

O controle interno da Administração Pública Brasileira, por exemplo, possui dois eixos de atuação, os quais têm finalidades distintas, mas complementares entre si:

naquele ano. A CEI foi oficialmente instalada em 4 de fevereiro de 1994. Era composta de representantes de diversos segmentos sociais. 
1) Controle interno de fiscalização: engloba as atividades de fiscalização, auditoria e avaliação de gestão. Em âmbito federal, por exemplo, é exercida pela Controladoria Geral da União (CGU), a qual possui a prerrogativa de identificar práticas ilegais, dentro da administração federal ou órgãos financiados por ele, a fim de aplicar as sanções legais, de forma a garantir a legalidade das ações públicas. Sistemas com igual finalidade são encontrados, também, em estados e municípios;

2) Controle interno de administração: desempenha atividades de cunho financeiro e contábil e funciona, no caso da União, a cargo da Secretaria do Tesouro Nacional (STN), e nos estados e municípios órgãos com prerrogativas semelhantes, os quais visam munir os governos de informações referentes às contas públicas, viabilizando a maximizaçãode seu desempenho, procurando racionalizar o conjunto de suas ações, conciliando receitas e despesas, garantindo, assim, uma boa gerência. Além desses controles internos mais gerais, existem ainda, nas estruturas internas de cada órgão de Estado, sistemas internos que desempenham auditorias e correições, visando instrumentalizar o administrador da maior quantidade de informações necessárias a seu trabalho ${ }^{4}$.

Pode-se dizer, ainda, que o controle interno, além de englobar inúmeras funções, possui também, sob certa ótica, o papel de co-gestor perante as administrações públicas. De fato, por sua natureza e com suas prerrogativas de controle, dando-se desde a elaboração do projeto de obras ou planejamento da gestão até a execução, ele acaba por influenciar diretamente as ações administrativas, dado que a interferência a priori pode significar alteração na lógica vigente. A Secretaria do Tesouro Nacional, por exemplo, pode influenciar o comportamento do Executivo Federal, quando Ihe sinaliza o quanto pode investir numa dada área em termos de política pública, levando em consideração, para isso, as informações quantitativas de suas receitas e despesas, como também restrições legais.

\footnotetext{
${ }^{4} E$ interessante notar que essas preocupações não se circunscrevem aos Estados modernos. A fim de exercer controle sobre suas colônias, por exemplo, a Espanha, quando metrópole, criou três tribunais de contas na América (em Los Reis-Peru, Cidade do México e Santa Fé-Nova Granada), visando a melhor eficiência financeira, segundo Lopez (1986). No Brasil, seguindo a mesma lógica, foram criados diversos sistemas, que buscavam dar maior controle à administração pública, como o Conselho da Fazenda, em 1808, que para Roure (apud SILVA, 1999), foi o embrião do Tribunal de Contas da União, e o Tesouro Nacional, criado com a promulgação da Constituição Imperial de 1824, encarregado de gerenciar as receitas e despesas da Fazenda Nacional. O foco principal, aqui, era coibir o excesso de despesas, ou seja, a racionalização dos gastos. É interessante notar também que, na mesma Constituição, já existiam dispositivos, que obrigavam o Governo a prestar contas de suas atividades ao Parlamento, o que demonstra que essa preocupação no Brasil não é recente ou apenas pósproclamação da República.
} 


\subsection{Controle externo}

No que se refere ao controle externo das ações degoverno, no caso brasileiro, em seus diferentes níveis, o Congresso Nacional, as assembleias legislativas, e câmaras de vereadores configuram exemplos de instituições que exercem tal função ${ }^{5}$. Ao analisar as diversas administrações, buscam averiguar sua lisura, de forma a munir de informações o conjunto da sociedade acerca da administração em curso. Segundo Almeida,

o controle externo da administração tem a função precípua de garantir a utilização dos recursos financeiros e do patrimônio do país em acordo com a manifestação legítima dos interesses nacionais. Cabe ao controle externo, devidamente apoiado pelo controle interno, agir como guardião do interesse público em relação às ações executadas com recursos governamentais (ALMEIDA, 2001, p. 29).

O Controle externo, como é concebido atualmente, tem origem em sistemas estruturados com base representativa, e objetiva limitar os poderes dos administradores, de maneira a coibir exageros e/ou irregularidades, que venham a praticar. A ocorrência desse tipo de controle configura, nas democracias representativas, o que a literatura chama de check and balances, no qual, pela separação dos poderes ocorre um tipo de controle intrínseco à própria engrenagem institucional, em que o poder controla o próprio poder, de forma a evitar desequilíbrio entre eles (ABRUCIO, 1994). Nas democracias representativas, segundo Anastasia (1999) "[...] os 'check and balances' são os principais mecanismos institucionais que facultam aos parlamentos o controle das burocracias [...]". Esse tipo de controle parlamentar, que exerce accountability horizontal, faz emergir uma rede de poderes relativamente autônomos, os quais têm a capacidade de questionar e, eventualmente, punir maneiras "impróprias" de se administrar o bem público (O'DONNELL, 1999, p. 32).

Os modelos de controle de origem representativa ou parlamentar manifestaram-se inicialmente, através de:

[...] comissões parlamentares especializadas para o desempenho de tarefas de fiscalização. Posteriormente, surge o modelo de instituições de assessoria ao Parlamento, para desempenhar essa tarefa de controle (SPECK, 2000, p. 31).

\footnotetext{
${ }^{5}$ Repare-se que, mesmo sendo um controle externo, quase todos esses órgãos fazem parte do próprio aparato de Estado. Diferentemente desse modelo, em que o controle é exercido por agentes do Estado, a CEI constituiu uma experiência de controle externo, em que as decisões eram tomadas por pessoas alheias a estrutura do Estado, ou seja, no limite, esse modelo se desenhou como um tipo de controle social, no qual a ação de coibir práticas contrárias às normas estabelecidas era exercida por pessoas advindas do corpo da própria sociedade.
} 
É nesse segundo momento que as instituições de controle financeiro são desenhadas e implementadas em diversos países. Os tribunais ou cortes de contas são estruturados para serem braços técnicos dos parlamentos. Ou seja, auxiliam-nos em análises econômico-financeiras, que estejam envolvendo recursos públicos.

Esse viés técnico do controle externo visa lançar mão de quadros qualificados para o exercício dessa função. Eles lidam com um tipo de trabalho bastante especializado, que requer uma formação e experiência de carreira específica, algo difícil de encontrar-se na grande maioria dos parlamentares, os quais, vindo de diversas áreas e para cumprir papéis políticos, não têm a obrigação legal de dominar tal conhecimento. Daí a necessidade de contarem com um braço técnico, a exemplo do TCU, TCE's e TCM's, que informem de maneira independente e precisa a respeito das finanças e das administrações públicas, cuja fiscalização está, em última análise, a cargo dos parlamentos: nacional, estadual e municipal.

Diferentemente do controle político, em que as casas parlamentares buscam fiscalizar e controlar a delegação dada aos executivos, verificando se as políticas, estabelecidas em conjunto e contidas nos planos orçamentários, estão sendo cumpridas, o técnico detém-se em analisar dados e acompanhar essas execuções, do ponto de vista legal, além de verificar se os princípios de economicidade, efetividade, eficiência e eficácia, pressupostos presentes na teoria da administração pública, estão sendo aplicados.

Os parlamentos lançam mão das cortes de contas, para informar-se com maior segurança acerca dos gastos públicos. Ao mesmo tempo, buscam o respaldo técnico necessário para legitimar suas decisões em relação à fiscalização dos gastos praticados com esses recursos.

Em âmbito municipal, o auxílio ao parlamento local no controle contábil, orçamentário, financeiro, patrimonial e operacional do poder público fica a cargo dos TCE's ou TCM's. Constitucionalmente, atribui-se às cortes de contas estaduais e municipais as mesmas prerrogativas destinadas ao TCU estabelecidas no título IV, seção IX, capítulo I da carta Magna de 1988. Nesta, está assegurado que as determinações expressas na seção IX,"[...] aplicam-se, no que couber, à organização, composição e fiscalização dos Tribunais de Contas dos Estados e do Distrito Federal, bem como dos Tribunais e Conselhos de Contas dos Municípios" (BRASIL, 1988).

Cabe ressaltar ainda, que mesmo as cortes de contas não estando vinculadas à estrutura do judiciário, o legislador constituinte conferiu a estes órgãos verdadeiros poderes jurisdicionais. É sobre este aspecto, portanto, que repousa a definição sugerida por Gualazzi, o qual entende que corte de conta "[...] é órgão administrativo parajudicial, funcionalmente autônomo, cuja função consiste em exercer, de ofício, o controle externo, fático e jurídico, sobre a execução financeiroorçamentária [...]" (apud FIGUEIRÊDO, 2003, p. 3).

De maneira geral, os TCE's e TCM's, dentro do sistema brasileiro de fiscalização e controle das finanças públicas, seguem a mesma lógica 
estabelecida na Constituição Federal de 1988 para o TCU. Compõem-se, adequando-se ao que dispõem o art. 73, § $2^{\circ}$ inciso I da Carta Magna, por ministros, no caso conselheiros, nomeados pelo Executivo e pelo Legislativo estadual - com a aprovação da própria Assembléia Legislativa uma parte dentre auditores e membros do Ministério Público junto ao Tribunal e outra preenchendo os requisitos de formação e conhecimentos específicos da função, sem esquecer, da obediência aos critérios de antiguidade e merecimento. Além disso, ainda dispõe de quadro próprio de pessoal com autonomia administrativa e financeira, o que the confere independência institucional.

A fiscalização econômico-financeira dos entes subnacionais, por sua vez, é exercida, via de rega, pelos TCE's, tendo em vista que a grande maioria dos municípios não possui cortes de contas próprias. Em relação aos municípios, objeto dessa pesquisa, cabe ao TCE da Paraíba à apreciação de suas contas.

O TCE paraibano foi criado em 1970. Seu quadro de pessoal é formado por conselheiros, procuradores, auditores, auxiliares de auditoria de contas públicas, assessores jurídicos, e pessoal administrativo, inclusive comissionados. Além dos 223 municípios localizados no estado da Paraíba, o TCE possuiu a prerrogativa de analisar o processo de prestação de contas do governo estadual, aproximadamente sessenta órgãos da administração estadual, dentre as quais, autarquias, fundações, dentre outras. Fiscaliza também órgãos da administração indireta de alguns municípios localizados no estado.

\section{Resultados e discussão}

Esta pesquisa caracteriza-se como descritivo-explicativo e buscou traçar um quadro geral das irregularidades existentes nas gestões municipais do estado da Paraíba e o posicionamento do TCE quanto a sua aprovação,testando-se variáveis que teoricamente explicam os casos de reprovação, utilizando-se para tal os números de casos de corrupção e impropriedades administrativas.

Tomou-se como objeto de análise o ente federativo municipal, tendo como universo a quase totalidade dos 223 municípios paraibanos que apesar de diferirem em relação ao quantitativo populacional e apresentarem algumas discrepâncias socioeconômicas, estão circunscritos dentro de um mesmo estado federado o que possibilitou produzir generalizações analíticas para toda a administração pública municipal nele existente ${ }^{6}$.

\footnotetext{
${ }^{6}$ Esta pesquisa foi desenvolvida em duas fases. Inicialmente, tomaram-se como objeto os 29 municípios da região do Cariri Paraibano, cujos resultados podem ser vistos em Melo e Pereira (2011), e Melo, Soares e Pereira (2011). Na segunda fase da pesquisa a investigação foi ampliada para a quase totalidade dos municípios do estado. No entanto, não foi possível levantar dados para 16 municípios ( $7 \%$ do total), quais sejam: Alagoinha, Boa Vista, Borborema, Brejo do Cruz, Caaporã, Cabedelo, Cacimbas, Campo de Santana, Marizópolis,
} 
A coleta dos dados deu-se a partir de uma abordagem qualitativa através da análise de documentos, que tiveram como foco os relatórios técnicos do TCE-PB sobre as prestações de contas das administrações municipais paraibanas em anos da gestão 2005/2008. Inicialmente, buscou-se eleger um ano base para cada gestão, e escolheu-se o de 2006. Porém, por indisponibilidade de documentos para todos os municípios neste ano, buscou-se informações nas prestações dos anos de 2005 e 2007, ficando o maior percentual de municípios analisados em 2006, conforme demonstrado na Tabela 2.

Tabela 2 - Número de Municípios Fiscalizados por Ano de Prestação de Contas

\begin{tabular}{l|c|c|c}
\hline Ano da prestação de contas & Número de municípios & \% & \% válida \\
\hline 2005 & 18 & 8,1 & 8,7 \\
\hline 2006 & 125 & 56,1 & 60,4 \\
\hline 2007 & 64 & 28,7 & 30,9 \\
\hline Total & 207 & 92,8 & 100,0 \\
\hline Valores omissos & 16 & 7,2 & \\
\hline Total & 223 & 100,0 & \\
\hline
\end{tabular}

Fonte: TCE/PB.

A estratégia metodológica de coleta de dados utilizada neste trabalho se apoiou em informações produzidas por sistemas de controle, que é amplamente utilizada para se mensurar corrupção (ANDVIG et al., 2000). Por ser, a corrupção, um fenômeno de difícil detecção,tornam-se necessárias prerrogativas especiais para sua adequada investigação, como também agentes dotados de know-how. Sistemas de controle institucionais contam com estas duas características, o que disponibiliza ao pesquisador material empírico de qualidade e confiabilidade para suas análises. Desta forma, os relatórios finais do TCE, nos quais, estão contidos as apreciações do Relator do processo, do Ministério Público (MP) e o Acordão final do Tribunal, representam uma fonte primordial de informações ${ }^{7}$.

Mulungu, Salgado de São Félix, Santarém, São José do Sabugi, Seridó, Serra Grande e Vieirópolis.

${ }^{7} \mathrm{O}$ rito processual das apreciações no interior do TCE/PB acontece da seguinte maneira: após, encaminhadas para o TCE, as contas passam pela análise dos técnicos da Divisão de Acompanhamento da Gestão Municipal (DIAGM), que efetuam a auditoria na região do respectivo município, os quais emitem um relatório inicial destacando, por consequência, os possíveis problemas encontrados no exercício financeiro em análise, inclusive denuncias posteriores. Em seguida, este relatório inicial trafega para avaliação do relator do processo, onde o mesmo procede com uma análise de todos os aspectos destacados inicialmente. Neste momento, muitas das irregularidades podem ser desconsideradas, tendo em vista a abertura de espaço para que os interessados possam exercer o seu direito constitucional de ampla defesa. Passada essa fase, o relator procede com sua averiguação considerando à defesa acostada aos autos do processo e justificando prático e teoricamente seus posicionamento e ponderações. Concomitantemente, o Ministério Público é chamado a opinar nos autos e, por conseguinte, emite um parecer que servirá também de referência para o posicionamento final do tribunal. Finalmente, as contas vão para a apreciação do corpo colegiado do tribunal que é 
Os dados coletados foram tratados quantitativamente, subsidiando a elaboração de um banco de dados, usando-se para isto os softwares Excel e o Statistical Package for the Social Sciences (SPSS), que permitiu estatísticas descritivas e inferenciais com vistas a atingir os objetivos da pesquisa.

Dos 223 municípios que compõem o universo da pesquisa, foi possível encontrar dados para 207. Destes, 179 , ou seja, $86,5 \%$ apresentaram irregularidades nas suas gestões, dentre os quais, $27,5 \%$ casos de corrupção e $86 \%$ impropriedades administrativas, conforme se pode constatar na Tabela 3. A somatória de casos de irregularidades aceitas após apresentadas pela equipe técnica do TCE e seus respectivos relatores somam 2.231. Em média nos municípios que foram identificadas impropriedades o número chega a 11,3 casos por municípios, enquanto que corrupção, a 3,8. Isto sugere que irregularidades em gestões municipais no estado analisado é a regra e não a exceção, diferenciando-se apenas no tipo.

Tabela 3 - Número de Municípios com Irregularidades Detectadas

\begin{tabular}{l|c|c|c|c|c|c|c|c|c}
\hline & \multicolumn{3}{|c|}{$\begin{array}{c}\text { Corrupção/ } \\
\text { Impropriedade }\end{array}$} & \multicolumn{3}{c|}{ Corrupção } & \multicolumn{3}{c}{ Impropriedades } \\
& $\mathrm{N}$ & $\%$ & $\begin{array}{c}\% \\
\text { válida }\end{array}$ & $\mathrm{N}$ & $\%$ & $\begin{array}{c}\% \\
\text { válida }\end{array}$ & $\mathrm{N}$ & $\%$ & $\begin{array}{c}\% \\
\text { válida }\end{array}$ \\
\hline $\mathrm{Sim}$ & 179 & 80,3 & 86,5 & 57 & 25,6 & 27,5 & 178 & 79,8 & 86,0 \\
\hline Não & 28 & 12,6 & 13,5 & 150 & 67,3 & 72,5 & 29 & 13,0 & 14,0 \\
\hline Total & 207 & 92,8 & 100,0 & 207 & 92,8 & 100,0 & 207 & 92,8 & 100,0 \\
\hline $\begin{array}{l}\text { Valores } \\
\text { omissos }\end{array}$ & 16 & 7,2 & & 16 & 7,2 & & 16 & 7,2 & \\
\hline Total & 223 & 100 & & 223 & 100 & & 223 & 100 & \\
\hline
\end{tabular}

Fonte: TCE/PB.

$\mathrm{Na}$ Tabela 4 seguem as irregularidades detectadas por tipo. É possível perceber que do total de 2.231 casos encontrados nas gestões administrativas paraibanas, aproximadamente $10 \%$ referem-se à corrupção, o restante, portanto, estão ligados a impropriedades. Estas estão distribuídas em subtipos, tais como licitações públicas, com pouco mais de $38 \%$ dos casos, descumprimento de legislações específicas contendo mais de $46 \%$ e irregularidades diversas somando quase $5 \%$.

composto por sete Conselheiros, os quais vão emitir e encaminhar para o Legislativo local o parecer final da corte, aprovando ou rejeitando as contas. Destaque-se, no entanto, que este parecer é meramente opinativo, pois quem vai julgar definitivamente as contas é a Câmara de Vereadores do respectivo município. 
Tabela 4 - Irregularidade por Tipo

\begin{tabular}{l|c|c|c}
\hline \multicolumn{2}{|c|}{ Irregularidades } & $\mathbf{N}$ & $\mathbf{\%}$ \\
\hline Corrupção & & 220 & 9,9 \\
\hline \multirow{2}{*}{ Impropriedades } & Licitação & 861 & 38,6 \\
\cline { 2 - 4 } & Descumprimento de norma legal & 1.044 & 46,8 \\
\cline { 2 - 4 } & Diversas & 106 & 4,8 \\
\hline Total & 2.231 & 100 \\
\hline
\end{tabular}

Desagregando as irregularidades por área de atuação da administração pública municipal (educação, saúde, infraestrutura, transporte, fiscal e outras) percebe-se que mais de $15 \%$ dos casos de corrupção concentram-se na educação e na saúde, no entanto, a grande maioria situa-se nas áreas transporte, fiscal e outras, esta última com um percentual de quase $40 \%$ (Tabela 5$)^{8}$. Os casos de impropriedades, por sua vez, distribuídos por tipo de irregularidade, seguem lógica semelhante de distribuição por área em relação aos eventos de corrupção. Como demonstrado na referida tabela, aproximadamente $50 \%$ das impropriedades em licitação ocorreram na área denominada de outras, os descumprimentos de lei, por sua vez, situam-se majoritariamente nas áreas fiscal e outras somando mais de $85 \%$ dos casos, e por último, as irregularidades denominadas de diversas foram detectadas, principalmente, na junção da educação e saúde, com pouco mais de $27 \%$ e, fiscal e outras somando mais de $42 \%$.

\footnotetext{
${ }^{8}$ Estão contemplados na área denominada fiscal aqueles casos que se relacionam direta ou indiretamente com a execução dos recursos orçamentários. Por exemplo, os casos onde ocorreram descumprimentos da Lei de responsabilidade Fiscal residem nesta área. Já na área denominada de outras se concentram aquelas irregularidades que não pertencem a nenhuma das áreas destacadas na pesquisa e que também não foi possível identificar quais seriam suas possíveis áreas.
} 
DOSSIÊ GOVERNABILIDADE, INFORMAÇÃO E FISCALIZAÇÃO POLÍTICA

Tabela 5 - Tipo de Irregularidade e Ocorrência por Área

\section{Irregularidades}

\begin{tabular}{|c|c|c|c|c|c|c|c|c|}
\hline \multirow{4}{*}{ Área } & \multirow{3}{*}{\multicolumn{2}{|c|}{ Corrupção }} & \multicolumn{6}{|c|}{ Impropriedades por Área } \\
\hline & & & \multicolumn{6}{|c|}{ Subtipo } \\
\hline & & & \multicolumn{2}{|c|}{ Licitação } & \multicolumn{2}{|c|}{ Descumprimento de lei } & \multicolumn{2}{|c|}{ Diversas } \\
\hline & $\mathbf{N}$ & $\%$ & $\mathbf{N}$ & $\%$ & $\mathbf{N}$ & $\%$ & $\mathbf{N}$ & $\%$ \\
\hline Educação & 23 & 10,5 & 28 & 3,3 & 78 & 7,5 & 15 & 14,2 \\
\hline Saúde & 13 & 5,9 & 69 & 8 & 23 & 2,2 & 14 & 13,2 \\
\hline Infraestrutura & 26 & 11,8 & 155 & 18 & 16 & 1,5 & 13 & 12,3 \\
\hline Transporte & 38 & 17,3 & 175 & 20,3 & 19 & 1,8 & 19 & 17,9 \\
\hline Fiscal & 36 & 16,4 & 4 & 0,5 & 429 & 41,1 & 24 & 22,6 \\
\hline Outras & 84 & 38,2 & 430 & 49,9 & 479 & 45,9 & 21 & 19,8 \\
\hline Total & 220 & 100 & 861 & 100 & 1044 & 100 & 106 & 100 \\
\hline
\end{tabular}

A avaliação da prestação das contas públicas nas gestões municipais é composta por três análises separadas, a do Relator do processo, a do Ministério Público e o posicionamento final da plenária do Tribunal de Contas. Na Tabela 6 percebe-se que os conselheiros do TCE seguem praticamente a recomendação do Relator. Por outro lado, em relação ao Ministério Público, há discrepâncias importantes. Isso sugere que o MP possui uma apreciação mais contundente quanto à aprovação de contas irregulares. Essa diferença chega a aproximadamente $20 \%$ dos casos.

Tabela 6 - Parecer do Relator, MP e Decisão do TCE

\begin{tabular}{c|c|c|c|c|c|c|c|c|c}
\hline \multirow{2}{*}{ PARECER } & \multicolumn{3}{|c|}{ RELATOR } & \multicolumn{3}{c|}{ MP } & \multicolumn{3}{c}{ TCE } \\
\cline { 2 - 10 } & $\mathrm{N}$ & $\%$ & $\begin{array}{c}\% \\
\text { Válida }\end{array}$ & $\mathrm{N}$ & $\%$ & $\begin{array}{c}\% \\
\text { Válida }\end{array}$ & $\mathrm{N}$ & $\%$ & $\begin{array}{c}\% \\
\text { Válida }\end{array}$ \\
\hline Favorável & 112 & 50,2 & 61,2 & 63 & 28,3 & 41,7 & 128 & 57,4 & 62,1 \\
\hline Contrário & 71 & 31,8 & 38,8 & 88 & 39,5 & 58,3 & 78 & 35,0 & 37,9 \\
\hline Total & 183 & 82,1 & 100,0 & 151 & 67,7 & 100,0 & 206 & 92,4 & 100 \\
\hline $\begin{array}{c}\text { Valores } \\
\text { omissos }\end{array}$ & 40 & 17,9 & & 72 & 32,3 & & 17 & 7,6 & \\
\hline Total & 223 & 100,0 & \multicolumn{3}{c|}{223} & 100,0 & & 223 & 100,0 \\
\hline
\end{tabular}

$\mathrm{Na}$ análise de contas de 151 municípios, houve concordância entre TCE e MP em $80 \%$ dos casos (Tabela 7). No entanto, em 30 municípios tiveram posicionamentos diferentes, o que demonstra diferenças de entendimento sobre a regularidade das contas em questão. 
DOSSIÊ GOVERNABILIDADE, INFORMAÇÃO E FISCALIZAÇÃO POLÍTICA

Tabela 7 - Número de Vezes que TCE e MP Divergiram Sobre Cada Gestão

\section{DIVERGÊNCIA ENTRE OS PARECERES DO TCE E MP}

\begin{tabular}{c|c|c|c}
\hline & $\mathrm{N}$ & $\%$ & \% válida \\
\hline Sim & 30 & 13,5 & 19,9 \\
\hline Não & 121 & 54,3 & 80,1 \\
\hline Total & 151 & 67,7 & 100,0 \\
\hline Valores omissos & 72 & 32,3 & \\
\hline Total & 223 & 100,0 & \\
\hline
\end{tabular}

Fonte: TCE/PB.

Dos pareceres emitidos pelo TCE recomendando aprovação das contas municipais, verifica-se que o MP discorda em $31 \%$ dos casos, ou seja, apenas um terço. Já quando a indicação é pela rejeição, o MP concorda em quase sua totalidade, perfazendo um total de $95 \%$ (Tabela 8).

Tabela 8 - Parecer do TCE por Parecer do MP

\begin{tabular}{c|c|c|c|c|c|c}
\hline \multirow{2}{*}{\multicolumn{2}{c|}{}} & \multicolumn{4}{c|}{ PARECER DO MP } & Total \\
\cline { 3 - 7 } \multicolumn{2}{c}{ PARECER DO TCE } & Favorável & \multicolumn{2}{c}{ Contrário } & \\
\cline { 3 - 7 } & Favorável & 60 & 69,0 & 27 & 31,03 & 87 \\
\cline { 3 - 7 } & Contrário & 3 & 4,7 & 61 & 95,31 & 64 \\
\hline \multicolumn{2}{c}{ Total } & 63 & 41,7 & 88 & 58,28 & 151 \\
\hline
\end{tabular}

Fonte: TCE/PB.

No conjunto dos municípios foi possível identificar quatro situações distintas: a) municípios sem nenhum tipo de irregularidade detectada ou se detectada pela equipe técnica, não acolhida pelos conselheiros no julgamento final; b) casos em que se detectou apenas corrupção; c) casos apenas de impropriedade; e d) municípios com corrupção e impropriedades. Esta distinção se faz necessária, por que é de se esperar que a depender da irregularidade detectada a intensidade do rigor no julgamento possa variar.

No primeiro grupo de municípios, a despeito do TCE não desaprovar nenhuma gestão, o MP foi desfavorável a três. Isto significa dizer que as irregularidades descartadas pela corte de contas não eram irrelevantes, já que provocou no MP um posicionamento de reprovação. No grupo de municípios que houve apenas casos de corrupção, ambas as instituições foram desfavoráveis. Onde houve apenas impropriedades, observa-se que - TCE emitiu parecer favorável para grande maioria dos municípios, enquanto que o MP em menor número. Nos municípios que ocorreram ambas as irregularidades, corrupção e impropriedade, as duas instituições recomendaram em sua maioria a rejeição das contas, com uma leve diferença positiva do MP (Tabela 9). 
Tabela 9 - Decisão do TCE e MP por Tipo de Irregularidade

\begin{tabular}{l|c|c|c|c|c|c|c|c|c|c}
\hline Irregularidade & \multicolumn{4}{|c|}{ Parecer do TCE } & \multicolumn{5}{c}{ Parecer do MP } \\
\hline & $\begin{array}{c}\text { Favo- } \\
\text { rável }\end{array}$ & $\%$ & $\begin{array}{c}\text { Contrá- } \\
\text { rio }\end{array}$ & $\%$ & Total & $\begin{array}{c}\text { Favo- } \\
\text { rável }\end{array}$ & $\%$ & $\begin{array}{c}\text { Contrá- } \\
\text { rio }\end{array}$ & $\%$ & Total \\
\hline $\begin{array}{l}\text { Ausentes/não } \\
\text { aceitas pelo TCE }\end{array}$ & 27 & 100 & 0 & 0,0 & 27 & 11 & 78,6 & 3 & 21,4 & 14 \\
\hline Corrupção & 0 & 0,0 & 1 & 100 & 1 & 0 & 0,0 & 1 & 100 & 1 \\
\hline Impropriedade & 95 & 77,9 & 27 & 22,1 & 122 & 50 & 56,8 & 38 & 43,2 & 88 \\
\hline $\begin{array}{l}\text { Corrupção e } \\
\text { impropriedade }\end{array}$ & 6 & 10,7 & 50 & 89,3 & 56 & 2 & 4,2 & 46 & 95,8 & 48 \\
\hline
\end{tabular}

Fonte: TCE/PB.

Em alguns casos, quando o número de irregularidades é alto ou mesmo se necessita de informações complementares, as investigações carecem de averiguação mais detalhada. Nesses casos os municípios são visitados e a investigação se dá in loco. A despeito dos custos desse tipo de procedimento, os resultados tendem a ser mais próximos da realidade, já que possibilita aos técnicos da corte contato direto com o objeto investigado, transcendendo os documentos que fazer parte da prestação de contas emitida para o Tribunal.

No levantamento de dados foi possível identificar informações sobre este tipo de inspeção em 132 municípios. Destes verificou-se que houve visita dos técnicos aos municípios na maioria dos casos (63,6\%). Dividindo os municípios em dois grupos, é possível confirmar a importância da ida dos técnicos aos municípios, pois em geral descobrem um número maior de irregularidades. Na Tabela 10, por exemplo, isso fica evidente. Em média, nos municípios visitados foram detectados mais que o triplo dos casos de corrupção quando comparados com os municípios que não tiveram a presença dos técnicos do TCE. Sob este aspecto, pode-se dizer que tal tipo de procedimento é fundamental quando se deseja combater as irregularidades, pois aumentam as chances de detecção, e consequentemente as de punição, o que pode afetar negativamente o nível de agencyloss.

Tabela 10 - Municípios com Fiscalização In Loco

\begin{tabular}{l|c|c|c|c}
\hline \multirow{2}{*}{ Irregularidades } & \multicolumn{2}{|c|}{ Inspeção in loco } & \multicolumn{2}{c}{ Sem inspeção in loco } \\
\cline { 2 - 5 } & $\begin{array}{c}\text { Número de } \\
\text { municípios }\end{array}$ & Média & $\begin{array}{c}\text { Número de } \\
\text { municípios }\end{array}$ & Média \\
\hline Casos de corrupção & 84 & 1,8 & 48 & 0,27 \\
\hline $\begin{array}{l}\text { Casos de } \\
\text { impropriedades }\end{array}$ & 84 & 12,8 & 48 & 8,25 \\
\hline Total & 84 & & 48 & \\
\hline
\end{tabular}

Fonte: TCE/PB. 
Um dos principais instrumentos de controle das gestões públicas no Brasil é a Lei 101/2000, Lei de Responsabilidade Fiscal (LRF). Esta busca gerar restrições para o comportamento dos gestores públicos os induzindo ao planejamento, à probidade e eficiência, o que no limite geraria ganhos substancias na qualidade da prestação de serviços públicos, isso quando cumprida adequadamente. No caso do estado da Paraíba, o que se verificou é que tal dispositivo legal não é respeitado por quase metade dos gestores públicos municipais (Tabela 11).

Tabela 11 - Municípios que Descumpriram a Lei de Responsabilidade Fiscal DESCUMPRIMENTO DA LRF

\begin{tabular}{c|c|c|c}
\hline & N & \% & \% válida \\
\hline Sim & 80 & 35,9 & 44,9 \\
\hline Não & 98 & 43,9 & 55,1 \\
\hline Total & 178 & 79,8 & 100,0 \\
\hline Valores omissos & 45 & 20,2 & \\
\hline Total & 223 & 100,0 & \\
\hline
\end{tabular}

Fonte: TCE/PB.

É interessante notar que, a despeito do descumprimento da LRF, tanto O TCE quando O MP emitiram pareceres favoráveis aparte dos municípios, que segundo os relatórios técnicos da corte e de seus respectivos relatores, cometeram a ilegalidade. Para estes O TCE aprovou a conta de $48,8 \%$, enquanto o MP foi favorável em $28,3 \%$. É de se questionar, portanto, a aplicação deste dispositivo legal e sua eficácia em constranger comportamentos indesejáveis na administração pública. Primeiro grande parte não cumpre, segundo, os que descumprem não são punidos em sua totalidade pelos órgãos de controle, pelo menos na unidade federativa foco da pesquisa.

Tabela 12 - Descumprimento da LRF e Pareceres do TCE e MP

\begin{tabular}{c|c|c|c|c|c|c|c|c|c|c}
\hline $\begin{array}{c}\text { Descum- } \\
\text { primento } \\
\text { da LRF }\end{array}$ & \multicolumn{4}{c|}{ Parecer do TCE } & \multicolumn{5}{c}{ Parecer do MP } \\
\hline & $\begin{array}{c}\text { Favo- } \\
\text { rável }\end{array}$ & $\%$ & $\begin{array}{c}\text { Con- } \\
\text { trário }\end{array}$ & $\%$ & Total & $\begin{array}{c}\text { Favo- } \\
\text { rável }\end{array}$ & $\%$ & $\begin{array}{c}\text { Con- } \\
\text { trário }\end{array}$ & $\%$ & Total \\
\hline Não & 73 & 74,5 & 25 & 25,5 & 98 & 40 & 53,3 & 35 & 46,7 & 75 \\
\hline Sim & 39 & 48,8 & 41 & 51,3 & 80 & 17 & 28,3 & 43 & 71,6 & 60 \\
\hline \multicolumn{10}{c|}{ Fonte: TCE/PB. }
\end{tabular}

Para testar as hipóteses sugeridas nesse trabalho foram elaborados dois modelos. No primeiro as variáveis dependentes inseridas são dicotômicas, tendo o valo 0 (zero) para ausência e o valor 1 (um) para presença de corrupção e ou impropriedade. A variável dependente também é dicotômica, qual seja 0 (zero) para contas com parecer favorável e 1 
(uma) para aqueles que foram rejeitas pela corte de contas, daí o uso de regressão logística binária. No segundo modelo houve um incremento de uma variável explicativa: prefeito filiado ao partido do governador no ano em que foi eleito (2004). A premissa é de que os governadores possuem influência junto aos tribunais de contas estaduais, isto por que, participam do processo de escolha de seus conselheiros. Dessa forma seria de se esperar que prefeitos que são do seu partido contassem com seu prestígio junto às cortes de contas estaduais, não tendo assim suas contas rejeitadas. Em ambos os modelos foram inseridas duas variáveis de controle, a população para o ano de 2000 e renda per capita de 2005.

É possível, após o teste, verificar que as duas variáveis sugeridas para explicar reprovações de contas municipais no estado da Paraíba nas gestões 2005-2008, foram corroboradas, no caso de corrupção com significância estatística de $1 \%$ e impropriedades de 5\% (Tabela 13). Isso demonstra que as variáveis realmente explicam as reprovações, mas com poder explicativo e intensidades diferentes. Isso é possível se verificar também nos valores do exp(B). A variável corrupção aumenta as chances de reprovação em 35 vezes, enquanto que impropriedades aproximadamente 13 .

Tabela 13 - Reprovação de Contas pelo TCE (Regressão Logística Binária)

\begin{tabular}{|c|c|c|c|c|c|c|}
\hline & \multicolumn{6}{|c|}{ Reprovação de Contas - TCE } \\
\hline & \multicolumn{3}{|c|}{ MODELO 1} & \multicolumn{3}{|c|}{ MODELO 2} \\
\hline CÓ-VARIÁVEIS & B & $E$ & $\operatorname{EXP}(B)$ & B & $E$ & $\operatorname{EXP}(B)$ \\
\hline Corrupção & $\begin{array}{c}3,572 * * \\
*\end{array}$ & 0,515 & $\begin{array}{c}35,57 \\
8\end{array}$ & $\begin{array}{c}3,579 * * \\
*\end{array}$ &, 515 & $\begin{array}{c}35,82 \\
5\end{array}$ \\
\hline Impropriedades & $2,602 * *$ & 1,154 & 13,490 & $2,599 * *$ & 1,157 & 13,447 \\
\hline $\begin{array}{l}\text { Correlig. do governador - } \\
2004\end{array}$ & & & &, 002 & ,016 & 1,002 \\
\hline População - 2000 & 0,000 & 0,000 & 1,000 & ,000 & ,000 & 1,000 \\
\hline Renda per capita - 2005 & 0,000 & 0,000 & 1,000 &, 000 & 000 & 1,000 \\
\hline Constante & $-3,308 * *$ & 1,354 & 0,037 & $-3,382$ & 1,400 &, 034 \\
\hline chi2 & 0,000 & & & 0,000 & & \\
\hline Log likelihood & 167,831 & & & 167,842 & & \\
\hline Cox \& Snell R2 & 0,401 & & & ,401 & & \\
\hline Nagelkerke R2 & 0,545 & & &, 545 & & \\
\hline $\mathrm{N}$ & 206 & & & 206 & & \\
\hline
\end{tabular}

Fonte: TCE/PB, SIMBRASIL; IBGE .

Obs.: $* p<0,01, * * p<0,05, * * * p<0,10$

Isto sugere que a corte de conta, a despeito, de terem aprovado, em alguns casos, contas em que se constatou corrupção, em geral possuem um posicionamento muito mais desfavorável à aprovação, se comparado com os casos de impropriedades. Isto tem a ver com o fato das cortes de conta em geral, tendo a noção que as burocracias municipais 
possuírem baixas qualificações e know-how, exercem um papel muito mais pedagógico do que punitivo, pelo menos nos casos de impropriedades.

$\hat{E}$ interessante notar, que no modelo 2, no qual foi inserida a variável política, em que se buscava averiguar se a corte de contas julgou de forma diferente os prefeitos correligionários do governador ou não, apresentou-se estatisticamente insignificante, apontando para inexistência desse critério nos julgamentos.

\section{Considerações Finais}

Gestores eficientes e comprometidos em preservar o erário é o que se espera de bons governos, os quais devem adotar estratégias para atender demandas emanadas da sociedade da melhor forma possível. E isso passa por otimizar os recursos escassos disponíveis e o enfrentamento dos problemas referente agencyloss, sobretudo, por bons mecanismos que garantam a responsabilização dos maus gestores, que cometam irregularidades em sua gestão.

Contatou-se nessa pesquisa que irregularidades são presente na grande maioria dos municípios e em grande volume, o que significa prejuízo para sociedade. Em maior número destacam-se os casos de impropriedades que figuram em aproximadamente $80 \%$ dos municípios. Nessa categoria de irregularidades destaca-se o descumprimento da LRF, visto que essa prática é presente em $45 \%$ dos municípios. Interessante notar que apenas metade daqueles gestores que descumpriram a LRF tiveram suas contas rejeitadas, e essa é uma das leis de maior relevância para restringir comportamentos irresponsáveis. Já corrupção foi detectada em $27 \%$ dos entes subnacionais localizados no estado.

Observou-se que nos municípios em que o TCE esteve presente a quantidade de irregularidades detectadas foi, em média, maior do que o grupo de municípios em que a corte baseou-se apenas nos documento enviados. Isso sugere que é imperativo que procedimento investigatórios in loco devam ser ampliado, quer seja para aumentar a capacidade de detecção, quer seja para onerar o custo no cálculo para ação ilícita.

Quanto ao julgamento das contas ressalte-se que o TCE em termos de julgamento é muito mais rigoroso com os casos de corrupção do que com os de impropriedade. Deve ser levado em consideração que as cortes de contas no Brasil têm ciência da qualidade da burocracia, e por isso tecem, em grande parte dos casos, apenas recomendações de correção, exercendo assim um papel meramente pedagógico. Isso pode explicar parte da discrepância de julgamento entre o TCE e MP. Este último em geral avalia e julga de forma mais rigorosa as contas se comparado com o primeiro.

Por último, acentue-se que as duas hipóteses testadas na pesquisa, corrupção e impropriedade administrativa foram corroboradas, explicando significativamente as reprovações de contas dos gestores municipais por parte do TCE. A existência de corrupção e impropriedade ampliam as 
chances de reprovação. Sob este aspecto, pode-se afirma que o TCE tem cumprido seu papel em recomendar reprovações de contas quando da existência de irregularidades, embora em alguns casos ainda mereçam ser mais rigorosos, aproximando-se dos posicionamentos do MP e reprovando todos os casos em que de fato há corrupção.

Clóvis Alberto Vieira de Melo é Doutor em Ciência Política pela UFPE, professor da Universidade Federal de Campina Grande.

E-mail: clovis.melo@ufcg.edu.br.

José Wilas Pereira é Graduando em Gestão Pública pela Universidade Federal de Campina Grande.

E-mail:wilaspj@gmail.com.

\section{Referências}

ABRUCIO, Fernando Luiz. Os barões da federação: o poder dos governadores no Brasil pós-autoritário. São Paulo: USP, 1994.

ALMEIDA, Francisco Carlos Ribeiro de. A verdadeira função do Tribunal de Contas da União no processo orçamentário. Revista do Tribunal de Contas da União, Brasília, v. 32, n. 87, p. 15-26, jan.-mar. 2001.

ANASTASIA, Fátima. Responsabilidade por controle parlamentar. Belo Horizonte: UFMG, 1999.

ANDVIG, Jens Chr et al. Research on Corruption. A policy oriented survey. Oslo: Commissioned by NORAD, 2000.

ARRETCHE, Martha T. S. Políticas Sociais No Brasil: descentralização em um Estado federativo. Revista Brasileira de Ciências Sociais, São Paulo, v. 14, n. 40, p. 111-141, jun. 1999.

BECKER, Gary. Crime and Punishment: An Economic Approach. Journal of Political Economy, Chicago, v. 76, n. 2, p. 169-217, abr. 1968.

BRASIL. Constituição da República Federativa do Brasil. Brasília: Senado, 1988.

BROLLO, Fernanda. Who Is Punishing Corrupt Politicians - Voters or the Central government? Evidence from the Brazilian Anti-Corruption Program. Milão, nov. 2008. (Working Paper n. 336). 
CAIDEN, Gerald E. Public Maladministration and Bureaucratic Corruption. Califórnia: University of Southern Califórnia, 1981.

FERRAZ, Claudio. FINAN, Frederico. Reelection Incentives and Polítical Corruption: Evidence from Brasil's Municipal Audit Report. In: Encontro Da Associação Brasileira De Ciência Política, 5., Belo Horizonte, 2006.

- Exposing Corrupt Politicians: The Effects of Brazil's PubliclyReleased Audits on Electoral Outcomes. (IZA Discussion Paper, n. 2836), Bonn, jun. 2007.

FIGUEIRÊDO, Carlos Maurício Cabral. A experiência do Tribunal de Contas de Pernambuco no estímulo à participação cidadã. In: Congreso Internacional del CLAD sobre la Reforma del Estado y de la Administración Pública, 8., Panamá, 2003.

GIDDENS, Anthony. O Estado-Nação e a violência: segundo volume de uma crítica contemporânea ao materialismo histórico. São Paulo: Edusp, 2001.

GOMES, Eduardo Granha Magalhães. Gestão por Resultados e eficiência na Administração Pública: uma análise à luz da experiência de Minas Gerais. 2009. 187 f. Tese (Doutorado em Transformações do Estado e Políticas) Programa de Pós-Graduação em Administração Pública e Governo, Fundação Getúlio Vargas, São Paulo, 2009.

JENSEN, Michel C.; MECKLING, William H. Theory of the Firm: Managerial Behavior, Agency Costs and Ownership Structure. Journal of Financial Economics, Cambridge, v. 3, n. 4, p. 305-360, out. 1976.

LEITE, Adailton Amaral Barbosa. Aumento da Corrupção Local e Limitação do Financiamento Federal: efeitos não antecipados do modelo de descentralização das políticas sociais pós-88. In: Seminário de Ciência Política e Relações Internacionais da UFPE, 5., Recife, 2009.

LINDBERG, Staffan I. Accountability: the core concept and its subtypes. (Working Paper, n. 1). London: Africa Power and Politics Programe, 2009.

LOPEZ, Luiz Roberto. História da América Latina. Porto Alegre: Mercado Aberto, 1986.

MELO, Clóvis Alberto Vieira de. Corrupção e Políticas Públicas: Uma Análise Empírica dos Municípios Brasileiros. 2010. 230 f. Tese (Doutorado em Ciência Política) - Programa de Pós-Graduação em Ciência Política, Universidade Federal de Pernambuco, Recife, 2010. 
MELO, Clóvis Alberto Vieira de; PEREIRA, José Willas. Corrupção, Ineficiência e Rejeição de Contas Municipais por Cortes de Contas. Revista Política e Trabalho, João Pessoa, a. XXVIII, v. 24, p. 129-14, 2011.

MELO, Clóvis Alberto Vieira de; SOARES, Kelly Cristina Costa; PEREIRA, José Willas. Padrões de Participação Política, Competição Eleitoral e Irregularidades em Gestões Municipais. In: MELO, Clóvis Alberto Vieira de; SOARES, Kelly Cristina Costa (Orgs.). Instituições, Gestão Pública e Desenvolvimento Sustentável: Perfil Socioeconômico e Política do Cariri Paraibano. Recife: Editora Nossa Livraria, 2011. v. 1. p. 137-179.

MENDES, Marcos. Análise das irregularidades na administração municipal do FUNDEF: Constatações do programa de fiscalização a partir de sorteios públicos da Controladoria-Geral da União. Transparência Brasil, dez. 2004.

O'DONNELL, Guilhermo. Accountability horizontal e novas poliaquias. Lua Nova, São Paulo, v. 44, p. 27-54, 1998.

PEREIRA, Jeronimo Rosário Tanan; CORDEIRO FILHO, José Bernardo. Rejeições de Prestação de Contas de Governos Municipais: o que está acontecendo? Contabilidade, Gestão e Governança, Brasília, v. 15, n. 1, p. 33-43, jan.-abr. 2012.

PRATT, Jown W., ZECKHAUSER, Richard J. Principals and agents: na overview. In: PRATT, Jown W., ZECKHAUSER, Richard J. Principals and agents: the structure of business. Boston: Harvard Business School Press, 1995. p. 1-36.

REZENDE, Claudia. Rejeição das contas das prefeituras cresce $130 \%$ em Minas Gerais. 2009. Disponível em: <https:www.radiomineira.com>. Acesso: 01 out. 2009.

SANTOS, Maria Helena Castro. Governabilidade, governança e democracia: criação de capacidade governativa e relação execultivo-legislativo no Brasil pós-constituínte. Dados, Rio de Janeiro, v. 40, n. 3, 1997.

SILVA, Arthur Adolfo Cotias e. O Tribunal de Contas da União na história do Brasil: evolução histórica, política e administrativa (1890 - 1998). In: TRIBUNAL DE CONTAS DA UNIÃO. Prêmio Serzedello Corrêa 1998: monografias vencedoras. Brasília: Instituto Serzedello Corrêa, 1999. p. 19141.

SOUTO, Humberto Guimarães. Congresso Nacional, Tribunal de Contas e controle externo. Revista do Tribunal de Contas da União, Brasília, v. 30, n. 79, p. 31-41, 1999. 


\section{DOSSIÊ GOVERNABILIDADE, INFORMAÇÃO E FISCALIZAÇÃO POLÍTICA}

SPECK, Bruno W. Inovação e rotina no Tribunal de Contas da União: o papel da instituição superior de controle financeiro no sistema político administrativo do Brasil. São Paulo: Fundação Konrad Adenauer, 2000.

Texto recebido em 23/10/2012.

Aprovado em 28/11/2012. 